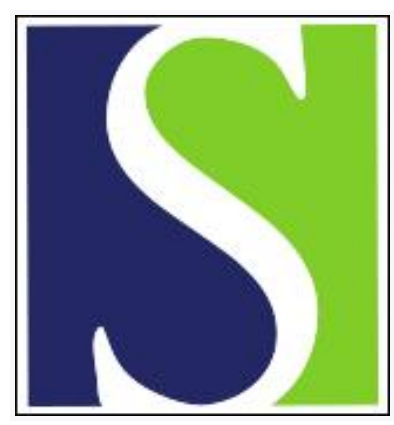

Scand J Work Environ Health 2005;31(1):36-43

https://doi.org/10.5271/sjweh.846

Issue date: Feb 2005

\title{
Cancer in the Norwegian printing industry
}

by Kvam BMN, Romundstad PR, Boffetta P, Andersen A

Affiliation: Cancer Registry of Norway, N-0310 Oslo, Norway. baard.kvam@kreftregisteret.no

Key terms: bladder cancer; cancer; cohort study; liver cancer; male; Norway; occupation; printing industry; social class; trade-union member

This article in PubMed: www.ncbi.nlm.nih.gov/pubmed/15751617

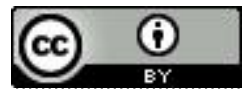




\title{
Cancer in the Norwegian printing industry
}

\author{
by Bård MN Kvam, MD, ${ }^{1}$ Pål Rikard Romundstad, PhD, ${ }^{1,2}$ Paolo Boffetta, MD, ${ }^{1,3}$ Aage Andersen ${ }^{1}$
}

\begin{abstract}
Kvam BMN, Romundstad PR, Boffetta P, Andersen A. Cancer in the Norwegian printing industry. Scand J Work Environ Health 2005;31(1):36-43.
\end{abstract}

\begin{abstract}
Objectives The aim of this study was to investigate cancer risk among Norwegian workers in the printing industry, particularly lung and bladder cancer.

Methods Cancer incidence was investigated from 1953 through 1998 in a cohort of 10549 male members of a trade union in the printing industry in Oslo and nearby areas. Rates from the region, were used to calculate standardized incidence ratios (SIR) separately for the skilled and unskilled workers. Smoking data from a sample of the cohort were utilized for evaluating the risk estimates of smoking-related cancers. Specific exposure data were not available.

Results Among the skilled workers, significantly elevated risks of cancer of the urinary bladder [standardized incidence ratio (SIR) 1.47, 95\% confidence interval (95\% CI) 1.19-1.79], liver (SIR 1.92, 95\% CI 1.15-2.99), pancreas (SIR 1.46, 95\% CI 1.07-1.94) and colon (SIR 1.27, 95\% CI 1.05-1.55) were observed, whereas an increased risk of lung cancer in this group was confined to those born before 1910. Among the unskilled workers, there were significantly increased risks of cancer of the mouth, esophagus, stomach, larynx, lung, and all sites.

Conclusions The study showed that workers in the printing industry were at increased risk of several types of cancer. In particular the increased risk of bladder cancer among the skilled workers is suggestive of an occupational cause. However, no specific agent could be identified as an occupational carcinogen. The results did not support the hypothesis of a generally increased risk of lung cancer. The risk pattern for unskilled workers may reflect confounding by nonoccupational factors.
\end{abstract}

Key terms bladder cancer; cohort study; liver cancer; male trade-union members; occupation; social class.

Workers in the printing industry are exposed to a variety of potentially hazardous agents, including aromatic amines, inks, organic solvents, dust, noise, night work, and, previously, lead (1-7). The constituents of ink include mineral oils and pigments, in particular carbon black in black inks. Exposure circumstances in this industry are complex and heterogeneous. A Danish overview of the graphical industry reported 300 different substances, of which 26 were known or suspected carcinogens (8).

An increased risk of cancer at various sites has been reported among workers in the printing industry, but the findings are not consistent $(2,8-16)$. In particular an increased risk for urinary bladder cancer has been reported in several studies (11, 17-21), although no association was reported in other investigations $(12,15,22)$. In addition, several studies have reported an increased risk of lung cancer (8, 17, 23-25), while other studies have failed to demonstrate any elevated risk $(2,26)$.
In 1996, an IARC (International Agency for Research on Cancer) working group evaluated occupational exposures in printing processes as possibly carcinogenic to humans, based on limited epidemiologic evidence for an increased risk of lung and bladder cancer (1).

The limitations of some of the available studies include small sample sizes, resulting in low statistical power, and an analysis of cancer mortality instead of cancer incidence. In the current study we investigated cancer risk in a cohort of more than 10000 members of a union of graphical workers from Oslo, Norway. Job titles recorded in the union files enabled a reasonable subdivision of the workers. We obtained data on cancer incidence from the Cancer Registry of Norway and chose an adequate reference population that geographically corresponded to the study population.

The aim of the study was to investigate the risk of cancer, in particular the risk of lung and bladder cancer,

Department of Public Health and General Practice, Norwegian University of Science and Technology, Trondheim, Norway.

3 Unit of Environmental Cancer Epidemiology, International Agency for Research on Cancer, Lyon, France.

Reprint requests to: Bård Kvam, Cancer Registry of Norway, N-0310 Oslo, Norway. [E-mail: baard.kvam@kreftregisteret.no] 
among male members of the Oslo branch of the Norwegian Union of Graphical Workers.

\section{Study population and methods}

\section{Study population}

The male members of the Oslo branch of the Norwegian Union of Graphical Workers constituted our study population. The Oslo branch covered graphical establishments in the city of Oslo and, with a few exceptions, establishments in the county of Akershus. In the time period from which the study population was recruited, $95 \%$ of the workers in the printing industry in this area were members of the union (Svein Mortensen, personal communication). The study population included all workers who were union members at any time in the period January 1953 to January 1975 with the known month and year at the start of membership. The person's age at the time of entering the union had to be below 67 years. For each person, the following data were recorded: name, date of birth, country of birth, job title, month and year at the start of membership, month and year at the end of membership, any change up to 1975 in either membership status or job title, and, if relevant, the date of emigration or death. On the basis of the demographic data of 11192 subjects, personal identification numbers were added from Statistics Norway. Altogether 643 workers remained unidentified, of whom 416 either were born abroad or were registered as emigrated in the union rolls. There were no indications of emigration of the other 227 unidentified workers. The remaining 10549 persons comprised the cohort, which has been previously studied with respect to the effect of paternal occupational exposures on offspring $(27,28)$.

\section{Linkage}

The cohort was linked with population and emigration registers at Statistics Norway to identify deceased and emigrated members. It was further linked with the Cancer Register to identify incident cases of cancer. Dates of emigration, death, or cancer diagnosis, as well as topographical and morphological codes of cancer, based on the seventh revision of the International Classification of Diseases (ICD-7) (29), were added. Linkage was performed using the unique personal identification number assigned to all people resident in Norway.

\section{Follow-up}

The date of the start of follow-up was 1 January 1953, the date of beginning membership, or the date of the person's 14th birthday, whichever came last; the date of the end of follow-up was the date of death, the date of emigration, or 1 January 1999, whichever came first. Loss to follow-up occurred on emigration. Persons who were lost to follow-up contributed person-time and cases until date of emigration.

\section{Exposure}

Potentially toxic agents occurring in the printing industry include organic solvents, mineral oils, pigments, resins, lead, and paper dust. Workers in this industry have been exposed to these factors through both inhalation and dermal contact.

Common exposures in traditional letterpress techniques include lead dust and fumes, benzene, toluene, xylene, carbon tetrachloride, and ink mist $(1,7)$. In the 1970s, the traditional letterpress gradually disappeared from the scene and was substituted by offset techniques, while rotogravure techniques, for publication purposes, in Norway were used until the end of the century. Solvent exposures in offset establishments included white spirits, methylene chloride, isopropanol, 1,1,1-trichloroethane, and ethanol. In rotogravure establishments, toluene represented the major solvent exposure, but other solvents were also present, including trichlororethylene (3). To our knowledge, benzene, as such, has not been used in the Norwegian printing industry, but there may have been exposure to it as a contaminant of toluene.

\section{Statistical analysis}

For each cancer site, the standardized incidence ratio (SIR), the ratio between observed and expected numbers of new cancer cases, was computed along with $95 \%$ confidence intervals $(95 \% \mathrm{CI})$. For standardized incidence ratios based on less than 100 observed cases, exact Poisson 95\% confidence intervals were used (30). For standardized incidence ratios based on 100 observed cases or more, the $95 \%$ confidence intervals were based on the approximation of the standard error of the $\log$ SIR. A result was regarded as statistically significant if the $95 \%$ confidence interval did not include 1 . The expected numbers were computed for 5-year observation periods as age-specific rates with 5-year age groups. The population of the city of Oslo and the county of Akershus, the area in which the members worked and lived for most of their lives, served as the reference population. The statistical package Epicure was used to compute the person-years, expected cases, and standardized incidence ratios (31).

The statistical analysis was performed separately for the skilled and unskilled workers. Four persons had held both a skilled and an unskilled job; their person-years 
were assigned to both groups. Table 1 reports selected jobs for the skilled and unskilled workers with corresponding tasks. Table 2 summarizes the mean and median year of birth, the start of membership, and the duration of membership of the cohort members.

For lung and bladder cancer and for the cancer sites with significantly increased risk among the skilled workers, the additional analysis of the standardized incidence ratio stratified on attained age, year of birth, and year of first membership was performed. In an additional analysis of alcohol-related cancers, the following cancer sites were included: tongue, mouth, pharynx, esophagus, liver, larynx.

An analysis of the risk of cirrhosis was performed by computing the standardized mortality ratio (SMR), the ratio of observed to expected deaths, with data from Statistics Norway, which has information on cause-specific mortality in Norway from 1960 to 1993 . The follow-up period, accordingly, for this analysis was 1960-1993.

\section{Smoking}

We obtained information on tobacco smoking for 311 cohort members who were involved in a survey on obstructive lung disease performed in Oslo in 1972 (32). We compared the age-adjusted prevalence of smoking

Table 1. Selected job titles and their respective typical worktasks.

\begin{tabular}{ll}
\hline Job titles & Worktasks \\
\hline $\begin{array}{l}\text { Skilled workers } \\
\text { Compositors }\end{array}$ & $\begin{array}{l}\text { Set type by hand or with machines } \\
\text { Printers }\end{array}$ \\
$\begin{array}{l}\text { Set, operate, clean, and oil printing machines, } \\
\text { clean printing plates, check print quality }\end{array}$ \\
$\begin{array}{l}\text { Reproduction } \\
\text { photographers }\end{array}$ & $\begin{array}{l}\text { Photograph originals for reproduction to printing } \\
\text { Mount film for copying to metal plates, etch }\end{array}$ \\
Bookbinders & $\begin{array}{l}\text { clichés, print tests of clichés } \\
\text { Bind books and periodicals, operate book-binding } \\
\text { machines, and related work }\end{array}$ \\
Unskilled workers & $\begin{array}{l}\text { Lay on paper, operate printing machines, clean } \\
\text { Printer's assistants plates }\end{array}$ \\
Assistants & $\begin{array}{l}\text { Carry rolls of paper, remove paper, clean, any odd } \\
\text { jobs } \\
\text { Operate folding machines, other tasks in the } \\
\text { finishing department }\end{array}$ \\
Bookbinder's &
\end{tabular}

Table 2. Mean and median duration of membership, year of birth, first year of membership and follow-up time.

\begin{tabular}{|c|c|c|c|c|c|c|}
\hline & \multicolumn{3}{|c|}{ Skilled workers } & \multicolumn{3}{|c|}{ Unskilled workers } \\
\hline & Median & Mean & SD & Median & Mean & SD \\
\hline $\begin{array}{l}\text { Duration of membership } \\
\text { (years) }\end{array}$ & 12.2 & 17.6 & 12.2 & 3.7 & 9.0 & 11.6 \\
\hline Year of birth & 1934 & 1928 & 19.7 & 1931 & 1928 & 17.1 \\
\hline Start of membership (year) & 1957 & 1951 & 18.4 & 1961 & 1958 & 12.2 \\
\hline Follow-up time (years) & 32.6 & 30.6 & 11.8 & 30.4 & 29.3 & 10.9 \\
\hline
\end{tabular}

among the cohort members with that of the males in the entire survey population $(\mathrm{N}=8128)$. Overall the age-adjusted proportion of ever smokers was $82 \%$ (95\% CI 78 $86 \%$ ) among the printing industry workers versus $72 \%$ in the total survey population. The proportions of ever smokers among the skilled and unskilled workers were $81.5 \%$ and $83.4 \%$, respectively. Among the trade union members born before 1935 , the proportion of ever smokers was $83 \%$ versus $81 \%$ in the total survey population, whereas among the workers born after 1935 the proportion of ever smokers was $82 \%$ versus $61 \%$ in the total survey population.

\section{Results}

During the follow-up, 318443 person-years of observation were accumulated, 4240 persons died, and 1652 incident cancer cases were registered.

The standardized incidence ratios for selected cancer sites are presented in table 3. Among the skilled workers, there was no excess risk for all cancer sites (SIR 1.03, 95\% CI 0.97-1.10), whereas among the unskilled workers there was a very slight excess (SIR 1.08, 95\% CI 1.00-1.17).

The risk of bladder cancer was significantly elevated among the skilled workers on the basis of 98 observed versus 67 expected cases (SIR 1.47). Seventeen of the cases occurred before the age of 55 years (SIR $1.81,95 \%$ CI 1.05-2.90) (table 4). Among the unskilled workers there was no excess risk.

No significant excess of lung cancer was found among the skilled workers. Among the skilled workers born before 1910, however, there was a significantly increased risk of lung cancer based on 74 cases versus 50 expected (SIR 1.48, 95\% CI 1.16-1.85) (table 4). The lung cancer risk was significantly elevated among the unskilled workers on the basis of 130 observed versus 88 expected cases (SIR 1.49, 95\% CI 1.25-1.76). A twofold risk was observed among the unskilled workers born in 1935 or later on the basis of 16 cases versus 8 expected (SIR 1.99, 95\% CI 1.14-3.24) (not shown in table). Furthermore, the unskilled workers, but not the skilled workers, experienced an excess of cancers of the oral cavity, esophagus, stomach, and larynx.

There was an excess risk for colon cancer among the skilled workers on the basis of 101 observed cases versus 79 expected (SIR 1.27, 95\% CI 1.05-1.55). Among the unskilled workers there was a significantly reduced risk for this cancer.

Among the skilled workers, there was an excess of liver cancer on the basis of 19 observed versus 10 expected cases (SIR 1.92), and, among the unskilled workers, there was a nonsignificant excess (SIR 1.62). In the 
Table 3. Observed number of selected cancer cases (0), standardized incidence ratios (SIR), and $95 \%$ confidence intervals (95\% CI) for the skilled and unskilled workers.

\begin{tabular}{|c|c|c|c|c|c|c|c|c|c|}
\hline \multirow[t]{2}{*}{ Site $^{a}$} & \multicolumn{3}{|c|}{ Skilled $(N=6553)^{b}$} & \multicolumn{3}{|c|}{ Unskilled $(\mathrm{N}=4000)^{\mathrm{c}}$} & \multicolumn{3}{|c|}{ Total $(\mathrm{N}=10549) \mathrm{d}, \mathrm{e}$} \\
\hline & 0 & SIR & $95 \% \mathrm{Cl}$ & 0 & SIR & $95 \% \mathrm{Cl}$ & 0 & SIR & $95 \% \mathrm{Cl}$ \\
\hline Lip (140) & 2 & 0.35 & $0.04-1.27$ & 2 & 0.58 & $0.07-2.11$ & 4 & 0.44 & $0.12-1.13$ \\
\hline Tongue (141) & 9 & 1.52 & $0.69-2.88$ & 4 & 1.10 & $0.30-2.81$ & 13 & 1.36 & $0.72-2.32$ \\
\hline Mouth (143-144) & 10 & 1.21 & $0.58-2.22$ & 11 & 2.12 & $1.06-3.79$ & 21 & 1.56 & $0.96-2.38$ \\
\hline Pharynx (145-146) & 5 & 0.48 & $0.16-1.12$ & 5 & 0.79 & $0.26-1.85$ & 10 & 0.60 & $0.29-1.10$ \\
\hline Esophagus (150) & 19 & 1.14 & $0.69-1.79$ & 20 & 2.08 & $1.27-3.22$ & 39 & 1.49 & $1.06-2.03$ \\
\hline Stomach (151) & 56 & 0.83 & $0.63-1.08$ & 53 & 1.41 & $1.06-1.85$ & 109 & 1.04 & $0.86-1.25$ \\
\hline Colon (153) & 101 & 1.27 & $1.05-1.55$ & 29 & 0.59 & $0.40-0.85$ & 130 & 1.01 & $0.85-1.21$ \\
\hline Rectum (154) & 46 & 0.93 & $0.68-1.24$ & 39 & 1.26 & $0.90-1.72$ & 85 & 1.06 & $0.85-1.31$ \\
\hline Liver $(155)^{\dagger}$ & 19 & 1.92 & $1.15-2.99$ & 10 & 1.62 & $0.78-2.98$ & 29 & 1.80 & $1.21-2.59$ \\
\hline Pancreas (157) & 47 & 1.46 & $1.07-1.94$ & 27 & 1.37 & $0.90-1.99$ & 74 & 1.42 & $1.12-1.79$ \\
\hline Nose (160) & 2 & 0.77 & $0.09-2.77$ & 2 & 1.25 & $0.15-4.52$ & 4 & 0.95 & $0.26-2.43$ \\
\hline Larynx (161) & 9 & 0.65 & $0.30-1.24$ & 18 & 2.03 & $1.20-3.21$ & 27 & 1.19 & $0.78-1.73$ \\
\hline Lung (162) & 150 & 1.12 & $0.95-1.31$ & 130 & 1.49 & $1.25-1.76$ & 280 & 1.26 & $1.12-1.42$ \\
\hline Prostate (177) & 160 & 0.92 & $0.78-1.07$ & 103 & 0.98 & $0.81-1.19$ & 263 & 0.94 & $0.83-1.06$ \\
\hline Testis (178) & 9 & 0.60 & $0.27-1.14$ & 6 & 0.71 & $0.26-1.55$ & 15 & 0.64 & $0.36-1.06$ \\
\hline Kidney (180) & 44 & 1.17 & $0.85-1.57$ & 29 & 1.20 & $0.81-1.73$ & 73 & 1.18 & $0.93-1.49$ \\
\hline Bladder (181) & 98 & 1.47 & $1.19-1.79$ & 42 & 0.97 & $0.70-1.31$ & 140 & 1.27 & $1.08-1.50$ \\
\hline Melanoma (190) & 39 & 0.91 & $0.65-1.25$ & 16 & 0.60 & $0.34-0.97$ & 55 & 0.79 & $0.60-1.03$ \\
\hline Other skin (191) & 33 & 1.09 & $0.75-1.53$ & 14 & 0.74 & $0.40-1.23$ & 47 & 0.95 & $0.70-1.27$ \\
\hline Brain (193) & 23 & 0.81 & $0.52-1.22$ & 11 & 0.63 & $0.31-1.13$ & 34 & 0.74 & $0.51-1.04$ \\
\hline Lymphoma (206) & 29 & 0.83 & $0.55-1.19$ & 20 & 0.93 & $0.57-1.43$ & 49 & 0.87 & $0.64-1.15$ \\
\hline Leukemia (207) ${ }^{g}$ & 32 & 0.85 & $0.58-1.20$ & 18 & 0.79 & $0.47-1.25$ & 50 & 0.83 & $0.62-1.09$ \\
\hline Other sites & 61 & 0.90 & $0.69-1.15$ & 40 & 0.97 & $0.69-1.32$ & 101 & 0.92 & $0.76-1.12$ \\
\hline All sites (140-207) & 1003 & 1.03 & $0.97-1.10$ & 649 & 1.08 & $1.00-1.17$ & 1652 & 1.05 & $1.00-1.10$ \\
\hline $\begin{array}{l}\text { a Code of the Internat } \\
\text { c } 117177 \text { person-yea } \\
\text { e Four persons contri } \\
{ }^{9} \text { Leukemia and other }\end{array}$ & & . & on, in par & & $\begin{array}{l}\text { b } 20 \\
\text { d } 31 \\
\text { f } \operatorname{lnc}\end{array}$ & $\begin{array}{l}\text { person-ye } \\
\text { person-ye }\end{array}$ & & & \\
\hline
\end{tabular}

Table 4. Observed number of cancer cases (0), standardized incidence ratios (SIR), and 95\% confidence intervals (95\% CI) for selected cancer sites among the skilled workers, stratified by year of birth, first year of membership, duration of membership in the trade union (with 20 years of lag) and age at time of diagnosis.

\begin{tabular}{|c|c|c|c|c|c|c|c|c|c|c|c|c|c|c|c|}
\hline & \multicolumn{3}{|c|}{ Colon } & \multicolumn{3}{|c|}{ Liver a } & \multicolumn{3}{|c|}{ Pancreas } & \multicolumn{3}{|c|}{ Lung } & \multicolumn{3}{|c|}{ Bladder } \\
\hline & 0 & SIR & $95 \% \mathrm{Cl}$ & 0 & SIR & $95 \% \mathrm{Cl}$ & 0 & SIR & $95 \% \mathrm{Cl}$ & 0 & SIR & $95 \% \mathrm{Cl}$ & 0 & SIR & $95 \% \mathrm{Cl}$ \\
\hline \multicolumn{16}{|l|}{ Year of birth } \\
\hline$<1910$ & 45 & 1.40 & $1.02-1.87$ & 8 & 1.72 & $0.74-3.40$ & 21 & 1.34 & $0.83-2.05$ & 74 & 1.48 & $1.16-1.85$ & 34 & 1.42 & $0.98-1.98$ \\
\hline $1910-1929$ & 47 & 1.52 & $1.11-2.02$ & 8 & 2.28 & $0.98-4.49$ & 16 & 1.38 & $0.79-2.25$ & 53 & 0.95 & $0.71-1.24$ & 41 & 1.44 & $1.03-1.96$ \\
\hline$\geq 1930$ & 9 & 0.56 & $0.26-1.06$ & 3 & 1.70 & $0.35-4.97$ & 10 & 1.97 & $0.95-3.63$ & 23 & 0.81 & $0.52-1.22$ & 23 & 1.59 & $1.01-2.38$ \\
\hline \multicolumn{16}{|l|}{ Starting Year } \\
\hline$<1925$ & 27 & 1.51 & $1.00-2.20$ & 5 & 1.99 & $0.65-4.65$ & 11 & 1.27 & $0.63-2.26$ & 28 & 1.12 & $0.74-1.61$ & 16 & 1.35 & $0.77-2.19$ \\
\hline $1925-1934$ & 18 & 1.28 & $0.76-2.02$ & 1 & 0.50 & $0.01-2.77$ & 5 & 0.76 & $0.25-1.77$ & 34 & 1.35 & $0.94-1.89$ & 18 & 1.42 & $0.84-2.25$ \\
\hline $1935-1944$ & 13 & 1.09 & $0.58-1.87$ & 6 & 3.96 & $1.45-8.61$ & 8 & 1.73 & $0.75-3.42$ & 28 & 1.35 & $0.89-1.95$ & 9 & 0.84 & $0.38-1.59$ \\
\hline 1945-1954 & 27 & 1.36 & $0.89-1.97$ & 1 & 0.48 & $0.01-2.67$ & 13 & 1.80 & $0.96-3.07$ & 39 & 1.05 & $0.75-1.44$ & 33 & 1.89 & $1.30-2.65$ \\
\hline$\geq 1955$ & 16 & 1.03 & $0.59-1.67$ & 6 & 3.35 & $1.23-7.29$ & 10 & 1.94 & $0.93-3.57$ & 21 & 0.80 & $0.50-1.23$ & 22 & 1.55 & $0.97-2.35$ \\
\hline \multicolumn{16}{|l|}{ Age (years) } \\
\hline$<55$ & 11 & 0.99 & $0.49-1.77$ & 2 & 1.63 & $0.20-5.88$ & 7 & 1.67 & $0.67-3.45$ & 17 & 0.84 & $0.49-1.35$ & 17 & 1.81 & $1.05-2.90$ \\
\hline $55-74$ & 58 & 1.29 & $0.98-1.67$ & 11 & 1.73 & $0.86-3.09$ & 32 & 1.59 & $1.09-2.24$ & 107 & 1.19 & $0.98-1.43$ & 59 & 1.50 & $1.14-1.93$ \\
\hline$\geq 75$ & 32 & 1.37 & $0.94-1.93$ & 6 & 2.58 & $0.95-5.61$ & 8 & 1.00 & $0.43-1.98$ & 26 & 1.09 & $0.71-1.59$ & 22 & 1.21 & $0.76-1.84$ \\
\hline
\end{tabular}

a Including intrahepatic bile ducts.

analysis stratified by starting year, the largest excess occurred after 1934 (table 4).

The risk of pancreatic cancer was significantly elevated among the skilled workers (SIR 1.46, 95\% CI
1.07-1.94) and was of similar magnitude among the unskilled workers (SIR 1.37, 95\% CI 0.90-1.99). The skilled workers employed after 1934 had the highest risks (table 4). 
In a pooled analysis of alcohol-related cancers, there was a significantly increased risk of these cancers among the unskilled workers (SIR 1.71, 95\% CI 1.332.17) that was not present among the skilled workers (SIR 1.09, 95\% CI 0.85-1.38). There was no increased risk of cirrhosis among the skilled workers on the basis of 16 observed cases versus 24 expected (SMR 0.66, $95 \%$ CI 0.37-1.06). For the unskilled workers there was a nonsignificantly elevated risk based on 23 cases versus 16 expected (SMR 1.43, 95\% CI 0.90-2.14).

\section{Discussion}

Among the skilled workers, an excess of bladder cancer was observed. In the same occupational group statistically significant excesses were observed also for cancer of the liver, pancreas, and colon. The increase in lung cancer incidence among the skilled workers was restricted to cohort members born before 1910. Among the unskilled workers significant excesses were observed for cancer of the oral cavity, esophagus, stomach, larynx, lung, and all sites.

The advantages of our study include its large size with more than 300000 person-years of observation and more than 1500 expected cancer cases. High-quality cancer incidence data from the Cancer Registry of Norway provide accurateness in the outcome measures. The use of union rolls as a base for a cohort as in our study may weaken external validity, but, in our study, this problem would have been limited due to a high percentage of organized labor. A major limitation of the study was the lack of detailed information on occupational exposure. This problem may have reduced our ability to detect potential associations between occupation and cancer risk and to identify specific carcinogens. Another limitation of the study was the inability to directly control for potential confounders.

Potential confounders for some of the aforementioned associations are social class, tobacco smoking, and alcohol drinking. Strong negative social gradients have been observed for stomach cancer in several studies $(33,34)$. Negative gradients have also been reported for cancer of the mouth, pharynx, esophagus, liver, larynx, and lung, while a positive gradient has been found for cancer of the colon and melanoma. Therefore, the pattern of results among unskilled workers in our study resembles a pattern associated with low socioeconomic status. The skilled workers, on the other hand, compared with the unskilled workers, had lower risk for some cancers associated with a negative social gradient (stomach and laryngeal cancer) and a higher risk of cancers with a positive gradient (colon cancer and melanoma). The results draw attention to the importance of controlling for social class, even in studies within a single industry.

Smoking is related to cancer of the lung, bladder, and several other organs (35). In our study there was a considerably higher proportion of smokers among both the skilled and unskilled workers than in the total survey population. However, among those born before 1935 , the group of people contributing the largest proportion of cancer cases, the difference was small. The skilled workers in this cohort experienced an excess of pancreatic cancer and bladder cancer but not of lung cancer, except for the workers in the oldest cohorts. It therefore seems likely that factors other than smoking accounted for the excess of pancreatic cancer and bladder cancer among the skilled workers. The difference in risk for lung cancer and other smoking-related cancers between the skilled and unskilled workers may be due to differences in smoking habits for the two groups, although available data suggest a similar prevalence of smokers. It can be speculated that after 1972 skilled workers, to a greater extent than unskilled workers, had given up smoking, following the pattern of differences between social classes. As the excess of lung cancer in our study was almost solely restricted to the unskilled workers, except for in the old cohorts, and the proportion of ever smokers was higher than in the general population, the increased risk of lung cancer observed in this study must be interpreted with caution with regard to occupational causes.

The alcohol drinking habits of the cohort were unknown. Cancer of the larynx, oral cavity, pharynx, esophagus, and liver are associated with alcohol consumption (36). Among the unskilled workers, there was a significantly elevated risk of all alcohol-related cancers, except for cancer of the pharynx. On the other hand, except for liver cancer, there was no excess of alcoholrelated cancers among the skilled workers. This finding, along with the absence of any increased cirrhosis mortality, indicates that excess alcohol consumption in general did not occur in this group of workers.

In general, cancer risk among unskilled workers seems to be confined to cancer sites expected to be influenced by confounders like social class, tobacco smoking, and alcohol drinking. These factors would not be expected to explain the excess cancer risk among skilled workers, and occupational exposure may therefore be a more likely cause in the latter group.

Several case-control studies have shown excess risks of bladder cancer in this industry, although few have been statistically significant. In the current study the excess of bladder cancer was only present for skilled workers. A study from England and Wales based on death certificates of men less than 50 years of age reported odds ratios for bladder cancer of 1.1 for exposure (high or low) to printing inks and 5.0 for high 
exposure (17). In a study from Italy, men ever employed in the printing industry had an odds ratio of 1.7 for bladder cancer, adjusted for smoking habits (4). A study from Yorkshire in the United Kingdom reported an elevated odds ratio of 3.1 (95\% CI 1.4-6.8) for this cancer for printers (21). A Swedish study presenting risk estimates adjusted for smoking and year of birth reported a relative risk of 2.0 (95\% CI 0.8-4.9) for urothelial cancer for exposure to carbon black, and odds ratios of 3.2 (95\% CI 0.4-27.1), 0.5 (95\% CI 0.1-2.1), and 3.6 (95\% CI 0.8-12.1) for estimated low, moderate, and high exposure to printing inks, respectively (37). Among cohort and register linkage studies, several incidence studies have shown increased risks of 1.3-1.4 for bladder cancer $(8,20,23,38)$, and also some mortality studies have shown excess risks of this magnitude $(2,11)$ although other mortality studies have failed to detect any increased risk $(12,14,39)$.

It is recognized that exposure to aromatic amines may result in an increased risk of bladder cancer, but, even though there has been use of such chemicals in the printing industry, it is not clear to what extent they may have contributed to the increased risks in the current and other studies. Other occupations and industries with mixed exposures, including exposures to pigments, have shown an increased risk for bladder cancer (4, 18, 22, 40-50).

An increased risk of lung cancer in the printing industry has been reported in several studies, and ink mist has been suggested as an etiologic agent for lung cancer (24). In our study there was no overall increase among skilled workers. The excess of lung cancer among the oldest cohorts, together with an absence of excess among younger cohorts, may indicate a shift in occupational exposures over time, but the result may also be due to chance or uncontrolled confounding by smoking.

An increased risk of colon cancer has been reported in cohort and record linkage studies in the printing industry $(8,11,16,48,51)$, and, in a case-control study, colon cancer was reported with a nearly twofold increase among workers in the printing industry (52). Mineral oil is a candidate as a causative agent as it is one of the constituents of ink, and there is some evidence of an increased risk of cancer of the gastrointestinal tract among workers exposed to mineral oils $(53,54)$. On the other hand, colon cancer risk has been associated with a positive social gradient, and the excess among skilled workers in our study may, in part, be attributed to an effect of social class.

There was a marked excess of cancer of the liver among the skilled workers. Cancer of the liver is associated with alcohol consumption (36). As neither the risk of the other alcohol-related cancers combined nor the risk of cirrhosis was increased among the skilled workers, it seems unlikely that alcohol consumption can explain the excess. There has been, and still is, a heavy use of organic solvents in the printing industry. Epidemiologic studies have reported excesses of cancer of the liver among persons exposed to organic solvents (5557). Such exposures may have contributed to the excess of liver cancer in our study. Elevated risks of liver cancer among workers in the printing industry have been reported in some studies from Nordic countries $(8,15$, 38 ), while few other studies do so, although two studies from the United States $(11,16)$ reported excesses of liver cancer. Differences in exposures between study populations could account for the discrepancy in the risk estimates. However, an excess of liver cancer due to an occupational cause may more easily be detected in a study conducted in a low incidence population using incidence data, as is the case in our study.

No major risk factor except tobacco has been established for pancreatic cancer, a further cancer site with an increased incidence among skilled workers. There is no evidence of a consistent social differential for pancreatic cancer, nor is there is evidence of a direct carcinogenic effect of alcohol drinking. An excess of pancreatic cancer was reported among printers with more than 10 years of employment in a hospital-based casecontrol-study (58), and a population-based case-control study reported a moderate, statistically significant increase in pancreatic cancer risk in the printing industry (59), but most studies in the printing industry report no excess of this cancer. Pancreatic cancer has been reported with elevated risks also in other mixed exposure circumstances including those for chemical workers, rubber workers, and paper and pulp workers (60). Organic solvents have been associated with pancreatic cancer risk $(61,62)$, as has dyes $(60)$. Although our results are suggestive of an association between pancreatic cancer risk and employment in the printing industry, they can also be due to chance.

Although the excess cancer risk among the unskilled workers could have been due to confounding, an effect of occupational exposures should not be ruled out, as, in some occupational settings, the latest arrived unskilled worker gets the worktasks with the highest exposures. In particular, the unskilled workers experienced an excess of cancers of the liver, pancreas, and kidney, neoplasms potentially associated with organic solvent exposure.

The printing industry has changed greatly in Norway over the past 20 years, including digitalization of the prepress processes. The findings in our study may, therefore, not be relevant to the printing industry today. However, the exposure experienced by this study population may still occur today in less developed countries, and artists in many countries are still using some of the traditional techniques.

The standardized incidence ratio for all cancer sites was close to unity. This finding may indicate that an 
appropriate reference population was chosen, using rates from Oslo and Akershus as the basis for the expected cases. The printing industry is traditionally an urban industry. Approximately $60 \%$ of the members of the Norwegian Union of Graphical Workers are members of its Oslo branch, while one quarter of the general population of Norway lives in the same area. In studies of this industry, on a national level, problems with the correct choice of a reference population may arise because the geographic settlement pattern of the whole population may differ from that of the workers in the industry. In our study the use of national rates would have yielded (eg, for skilled workers) a standardized incidence ratio of 3.5 for liver cancer (compared with 1.9 in table 3).

Our study strongly suggests that printing industry workers are at increased risk of several types of cancer. The risk pattern among the unskilled workers did not allow any firm conclusion of an occupational etiology, as some of the cancers are greatly influenced by nonoccupational factors like alcohol drinking and tobacco smoking. Among the skilled workers, the risk pattern differed, and some of the excess cancer risk was probably due to occupational exposure.

\section{Acknowledgments}

We would like to thank Steinar Webjørnsen and Torill Woldbæk for the information on exposures in the printing industry, Sven-Erik Skarsbø, Per Thorkildsen and Steinar Webjørnsen for the classification of job titles, Jan-Ivar Martinsen for his valuable help with the data management and analysis, Tom Kristian Grimsrud for his valuable comments on an early version of the manuscript, and Svein Mortensen and Olav Boye for the trade union related information.

The project received financial support from the Working and Environment Fund of the Confederation of Norwegian Business and Industry and from the Ministry of Local Government and Regional Development.

\section{References}

1. International Agency for Research on Cancer (IARC). Printing processes and printing inks. Lyon: IARC; 1996. IARC monographs on the evaluation of carcinogenic risks to humans, vol 65 .

2. Michaels D, Zoloth SR, Stern FB. Does low-level lead exposure increase risk of death? a mortality study of newspaper printers. Int J Epidemiol 1991;20:978-83.

3. Thorud, S, Hågensen IT. Løsemiddelmålinger i grafisk industri [Measurements of solvents in the graphical industry]. Oslo: Yrkeshygienisk institutt; 1981.

4. Vineis P, Magnani C. Occupation and bladder cancer in males: a case-control study. Int J Cancer 1985;35:599-606.

5. Webjørnsen S. Kjemiske produkter i grafisk, del 1: offset [Chemical products in the graphical trade, part 1: offset]. Oslo: Institutt for grafiske medier; 2000.

6. Austbø I, Leira HL, Johansen H, Webjørnsen S. Kjemiske produkter i grafiske avdelinger i norske aviser [Chemical products in graphical departments in Norwegian newspapers]. Oslo: Aftenpostens Grafiske Klubb; 1984.

7. Beaulieu HJ. Newspaper production is plagued by excessive noise and aerosols. Occup Health Saf 1978;47:62-70.

8. Lynge E, Rix BA, Villadsen E, Andersen I, Hink M, Olsen E, et al. Cancer in printing workers in Denmark. Occup Environ Med 1995;52:738-44.

9. Bertazzi PA, Zocchetti C. A mortality study of newspaper printing workers. Am J Ind Med 1980;1:85-97.

10. Bulbulyan MA, Ilychova SA, Zahm SH, Astashevsky SV, Zaridze DG. Cancer mortality among women in the Russian printing industry. Am J Ind Med 1999;36:166-71.

11. Greene MH, Hoover RN, Eck RL, Fraumeni JF. Cancer mortality among printing plant workers. Environ Res 1979;20:6673.

12. Leon DA. Mortality in the British printing industry: a historical cohort study of trade union members in Manchester. Occup Environ Med 1994;51:79-86.

13. Lloyd JW, Decoufle P, Salvin LG. Unusual mortality experience of printing pressmen. J Occup Med 1977;19:543-50.

14. Paganini-Hill A, Glazer E, Henderson BE, Ross RK. Causespecific mortality among newspaper web pressmen. J Occup Med 1980;22:542-4.

15. Rafnsson V. Incidence of cancer among bookbinders, printers, photoengravers, and typesetters. Occup Environ Med 2001;58:523-7.

16. Zoloth SR, Michaels DM, Villalbi JR, Lacher M. Patterns of mortality among commercial pressmen. J Natl Cancer Inst 1986;76:1047-51.

17. Coggon D, Pannett B, Acheson ED. Use of job-exposure matrix in an occupational analysis of lung and bladder cancers on the basis of death certificates. J Natl Cancer Inst 1984;72:61-5.

18. Gonzalez CA, Lopez-Abente G, Errezola M, Escolar A, Riboli E, Izarzugaza I, et al. Occupation and bladder cancer in Spain: a multi-centre case-control study. Int J Epidemiol 1989;18:569-77.

19. Kunze E, Chang-Claude J, Frentzel-Beyme R. Life style and occupational risk factors for bladder cancer in Germany: a case-control study. Cancer 1992;69:1776-90.

20. Olsen JH, Jensen OM. Occupation and risk of cancer in Denmark: an analysis of 93810 cancer cases, 1970-1979. Scand J Work Environ Health 1987;13 Suppl 1:1-91.

21. Cartwright R. Occupational bladder cancer and cigarette smoking in West Yorkshire. Scand J Work Environ Health 1982;8 Suppl 1:79-82.

22. Silverman DT, Levin LI, Hoover RN, Hartge P. Occupational risks of bladder cancer in the United States I: white men. J Natl Cancer Inst 1989;81:1472-80.

23. Malker HS, Gemne G. A register-epidemiology study on cancer among Swedish printing industry workers. Arch Environ Health 1987;42:73-82.

24. Leon DA, Thomas P, Hutchings S. Lung cancer among newspaper printers exposed to ink mist: a study of trade union members in Manchester, England. Occup Environ Med 1994;51:87-94.

25. Moss E, Scott TS, Atherley GR. Mortality of newspaper workers from lung cancer and bronchitis 1952-66. Br J Ind Med 
1972;29:1-14.

26. Dunn JE, Weir JM. A prospective study of mortality of several occupational groups: special emphasis on lung cancer. Arch Environ Health 1968;17:71-6.

27. Kristensen P, Andersen A. A cohort study on cancer incidence in offspring of male printing workers. Epidemiology 1992;3:610.

28. Kristensen P, Irgens LM, Daltveit AK, Andersen A. Perinatal outcome among children of men exposed to lead and organic solvents in the printing industry. Am J Epidemiol 1993;137:134-44.

29. World Health Organization (WHO). International Classification of Diseases, Seventh Revision. Geneva: WHO; 1957.

30. Breslow NE, Day NE. Statistical methods in cancer research, vol II: the design and analysis of cohort studies. Lyon: International Agency for Research on Cancer (IARC); 1987. IARC Scientific Publications, no 82.

31. Preston DL, Lubin JH, Piercer DA, McConney CE. Epicure. Seattle (WA): Hirosoft International Corporation; 1996

32. Gulsvik A. Obstructive lung disease in an urban population: methodological aspects and prevalence estimates of a crosssectional survey, and some possible risk factors in Oslo, Norway. Oslo: University of Oslo; 1979.

33. Faggiano F, Partanen T, Kogevinas M, Boffetta P. Socioeconomic differences in cancer incidence and mortality. In: Kogevinas M, Pearce N, Susser M, Boffetta P. Social inequalities and cancer. Lyon: International Agency for Research on Cancer (IARC); 1997. IARC Scientific Publications, no 138:65176.

34. Tomatis, L, editor. Cancer: causes, occurrence and control. Lyon: International Agency for Research on Cancer (IARC); 1990. IARC Scientific Publications, no 100.

35. International Agency for Research on Cancer (IARC). Tobacco smoking. Lyon: IARC; 1986. IARC monographs on the evaluation of carcinogenic risks to humans, vol 38 .

36. International Agency for Research on Cancer (IARC). Alcohol drinking. Lyon: IARC; 1988. IARC monographs on the evaluation of carcinogenic risks to humans, vol 44.

37. Steineck G, Plato N, Gerhardsson M, Norell SE, Hogstedt C. Increased risk of urothelial cancer in Stockholm during 198587 after exposure to benzene and exhausts. Int J Cancer 1990;45:1012-7.

38. Andersen A, Barlow L, Engeland A, Kjaerheim K, Lynge E, Pukkala E. Work-related cancer in the Nordic countries. Scand J Work Environ Health 1999;25 Suppl 2:1-116.

39. Greenberg M. A proportional mortality study of a group of newspaper workers. Br J Ind Med 1972;29:15-20.

40. Cordier S, Clavel J, Limasset JC, Boccon-Gibod L, Le Moual $\mathrm{N}$, Mandereau L, et al. Occupational risks of bladder cancer in France: a multicentre case-control study. Int J Epidemiol 1993;22:403-11.

41. Steenland K, Burnett C, Osorio AM. A case-control study of bladder cancer using city directories as a source of occupational data. Am J Epidemiol 1987;126:247-57.

42. Cole P, Hoover R, Friedell GH. Occupation and cancer of the lower urinary tract. Cancer 1972;29:1250-60.

43. la Vecchia C, Negri E, D'Avanzo B, Franceschi S. Occupation and the risk of bladder cancer. Int $\mathrm{J}$ Epidemiol 1990;19:264-8.

44. Matanoski GM, Stockwell HG, Diamond EL, Haring-Sweeney M, Joffe RD, Mele LM, et al. A cohort mortality study of painters and allied tradesmen. Scand J Work Environ Health 1986;12:16-21.
45. Claude JC, Frentzel-Beyme RR, Kunze E. Occupation and risk of cancer of the lower urinary tract among men: a casecontrol study. Int J Cancer 1988;41:371-9.

46. Siemiatycki J, Dewar R, Nadon L, Gerin M. Occupational risk factors for bladder cancer: results from a case-control study in Montreal, Quebec, Canada. Am J Epidemiol 1994;140:106180.

47. Malker HS, McLaughlin JK, Silverman DT, Ericsson JL, Stone BJ, Weiner JA et al. Occupational risks for bladder cancer among men in Sweden. Cancer Res 1987;47:6763-6.

48. Pearce NE, Howard JK. Occupation, social class and male cancer mortality in New Zealand, 1974-78. Int J Epidemiol 1986;15:456-62.

49. Lynge E, Thygesen L. Use of surveillance systems for occupational cancer: data from the Danish National system. Int J Epidemiol 1988; 17:493-500.

50. Baxter PJ, McDowall ME. Occupation and cancer in London: an investigation into nasal and bladder cancer using the Cancer Atlas. Br J Ind Med 1986;43:44-9.

51. Pukkala, E. Cancer risk by social class and occupation: a survey of 109,000 cancer cases among Finns of working age. Basel (Switzerland): Karger; 1995. Contributions to Epidemiology and Biostatistics, vol 7.

52. Brownson RC, Zahm SH, Chang JC, Blair A. Occupational risk of colon cancer: an analysis by anatomic subsite. Am J Epidemiol 1989;130:675-87.

53. International Agency for Research on Cancer (IARC). Mineral oils. Lyon: IARC; 1984. IARC monographs on the evaluation of carcinogenic risks to humans, vol 33.

54. Tolbert PE. Oils and cancer. Cancer Causes Control 1997;8:386-405.

55. Blair A, Hartge P, Stewart PA, McAdams M, Lubin J. Mortality and cancer incidence of aircraft maintenance workers exposed to trichloroethylene and other organic solvents and chemicals: extended follow up. Occup Environ Med 1998;55:161-71.

56. Spirtas R, Stewart PA, Lee JS, Marano DE, Forbes CD, Grauman DJ, et al. Retrospective cohort mortality study of workers at an aircraft maintenance facility I: epidemiological results. Br J Ind Med 1991;48:515-30.

57. Hernberg S, Kauppinen T, Riala R, Korkala M-L, Asikainen $\mathrm{U}$. Increased risk for primary liver cancer among women exposed to solvents. Scand J Work Environ Health 1988;14:356-65.

58. Siemiatycki J. Risk factors for cancer in the workplace. Boca Raton (CA): CRC Press; 1991.

59. Kernan GJ, Ji BT, Dosemeci M, Silverman DT, Balbus J, Zahm SH. Occupational risk factors for pancreatic cancer: a case-control study based on death certificates from 24 U.S. states. Am J Ind Med 1999;36:260-70.

60. Weiderpass E, Partanen T, Kaaks R, Vainio H, Porta M, Kauppinen T, et al. Occurrence, trends and environment etiology of pancreatic cancer [review]. Scand J Work Environ Health 1998;24:165-74.

61. Ojajärvi A, Partanen T, Ahlbom A, Boffetta P, Hakulinen T, Jourenkova N, et al. Risk of pancreatic cancer in workers exposed to chlorinated hydrocarbon solvents and related compounds: a meta-analysis. Am J Epidemiol 2001;153:841-50.

62. Ojajärvi IA, Partanen TJ, Ahlbom A, Boffetta P, Hakulinen T, Jourenkova N, et al. Occupational exposures and pancreatic cancer: a meta-analysis. Occup Environ Med 2000;57:316-24.

Received for publication: 15 December 2003 